\title{
Kranke Herzen sollen sich selbst heilen
}

Kranke Herzen sollen sich zukünftig selbst heilen. In enger Zusammenarbeit haben Wissenschaftler der Schüchtermann-Klinik Bad Rothenfelde und des Max-PlanckInstituts für Herz- und Lungenforschung Bad Nauheim ein Protein identifiziert, das maßgeblich die Heilungskräfte in Herzmuskelzellen reguliert.

Bei Erkrankungen des Herzmuskels wie zum Beispiel beim Herzinfarkt laufen in den Zellen automatisch Umbauprozesse $\mathrm{ab}$, die die fatalen Folgen für das Organ begrenzen sollen. Das von den Wissenschaftlern der Schüchtermann-Klinik und des Max-Planck-Instituts entdeckte Protein stimuliert die Rückbildung einzelner Herzmuskelzellen in ihre Vorläufer. „Wir möchten nun mit Hilfe dieses Proteins die Selbstheilungskräfte des
Herzens verbessern“, so Prof. Dr. Henning Warnecke, Chefarzt der Herzchirurgie in der Schüchtermann-Klinik: „Um einen geschädigten Herzmuskel, wie er sich beispielsweise nach einem Infarkt darstellt, zu regenerieren, müssen die geschädigten Muskelzellen durch neue ersetzt werden. Dabei kann es sich je nach Schädigungsgrad um beträchtliche Zellzahlen handeln, die zu ersetzen sind.“ Laut Aussage der Wissenschaftler gibt dabei die Natur selbst den Weg vor: Bei einfacheren Wirbeltieren, wie etwa dem Salamander, entwickeln sich überlebende gesunde Herzzellen zunächst in einen embryonalen Zustand zurück. Dabei werden Zellen produziert, die eine Reihe von Stammzellmarkern in sich tragen und ihre Zellteilungsaktivität wiedererlangen.
Auf diese Weise entstehen neue Zellen, die sich wiederum in Herzmuskelzellen umwandeln. Im Rahmen eines Umbaus des Muskelgewebes wird die Herzfunktion dann wiederhergestellt.

„Beim Menschen ist ein derart perfektionierter Reparaturmechanismus nicht vorhanden“, erläutert Prof. Dr. Thomas Braun vom Max-Planck-Institut für Herzund Lungenforschung. Vor einiger Zeit seien zwar Herz-Stammzellen entdeckt worden. Es sei aber umstritten, inwieweit diese für die Herzreparatur überhaupt eine Rolle spielen. Erst seit wenigen Jahren sei zudem bekannt, dass Prozesse, vergleichbar denen beim Salamander, im Säugerorganismus überhaupt existierten. Die gemeinsame Arbeitsgruppe entdeckte nun das Protein, das beim Säuger für die Steuerung dieser Rückentwicklung von Zellen in den embryonalen Zustand verantwortlich ist. Denn bei Gewebeproben aus dem Herzen von Infarktpatienten konnten die Wissenschaftler die hohe Konzentration des Proteins Oncostatin M feststellen, das unter anderem für die Rückentwicklung verschiedener Zelltypen zuständig ist. „Anhand bestimmter Änderungen in den Zellen konnten wir sehen, dass innerhalb von sechs Tagen nach der Behandlung mit Oncostatin M nahezu alle Herzmuskelzellen zurückgebildet waren“, sagt Prof. Dr. Braun: „Stattdessen konnten wir in den Zellen nun verschiedene Stammzellmarker nachweisen. Dies ist als ein Hinweis darauf zu werten, dass diese Zellen nun in einen Reparaturmodus umgeschaltet worden waren.“

Die Wissenschaftler aus Bad Rothenfelde und Bad Nauheim möchten im nächsten Schritt einen Weg finden, über den Oncostatin M gezielt therapeutisch eingesetzt werden kann. Ziel ist es, die Selbstheilung eines geschädigten Herzmuskels zu stärken und erstmals eine tatsächliche Wiederherstellung der Herzfunktion zu ermöglichen. „Bis zur konkreten klinischen Umsetzung dieser neu gewonnenen wissenschaftlichen Erkenntnisse beim akuten Herzinfarkt ist es allerdings noch ein langer Weg“, betont Prof. Dr. Warnecke. „Es kommt nun darauf an, dass wir den Anwendungsbereich definitiv bestimmen und potentielle negative Auswirkungen absolut ausschließen.“

Quelle: Pressemeldung Schüchtermann-Klinik Bad Rothenfelde und Max-Planck-Institut für Herz- und Lungenforschung Bad Nauheim 